\title{
The Durham Initiative for Stomach Health (DISH): a pilot community-based Helicobacter pylori education and screening study
}

Sydnee Crankshaw ${ }^{1}$, Julia Butt ${ }^{1,2}$, Jennifer M. Gierisch ${ }^{1,2,3}$, Nadine J. Barrett ${ }^{1,4,5}$, Sabrena Mervin-Blake ${ }^{5}$, Kevin Oeffinger ${ }^{1}$, Steven Patierno ${ }^{1,4,6,7}$, Valarie Worthy ${ }^{5}$, Ronald Godbee ${ }^{8}$ and Meira Epplein ${ }^{1,2,6^{*}}$ (D)

\begin{abstract}
Background: Approximately 15\% of all cancers are due to infection. The bacteria Helicobacter pylori is the single leading carcinogenic infectious agent and the main cause of stomach cancer. Prevalence of H. pylori, and, correspondingly, stomach cancer incidence and mortality, is significantly greater among African Americans than whites in the United States. In the present study, we conducted a pilot community-engaged H. pylori education and screening study in partnership with a predominantly African American church in Durham, North Carolina.

Methods: Initially, we consulted with community advisory boards and convened stakeholder meetings with local community members and primary care physicians. We then developed this pilot study through an iterative collaboration with church partners. Our main outcomes were feasibility and acceptability as measured by participation in a one-day H. pylori screening initiative, and participation in follow-up for those who tested positive. We also sought to determine prevalence and determinants of active H. pylori infection in this population.

Results: Community engagement informed the event logistics, messaging, educational materials provided, and follow-up plans. A total of 92 individuals participated in the primary study event, $25 \%$ of whom had a current $\mathrm{H}$. pylori infection. Of those, $87 \%$ returned for the follow-up events, among whom $70 \%$ had successfully cleared their infection.

Conclusions: Through community engagement, community-based H. pylori screening and stomach cancer prevention is feasible and acceptable. This is a necessary step in order to move stomach cancer prevention forward to population-based precision H. pylori screening and eradication.
\end{abstract}

Keywords: Cancer prevention, Stomach cancer, Helicobacter pylori, Education, Screening

\footnotetext{
* Correspondence: meira.epplein@duke.edu

${ }^{1}$ Cancer Control and Population Sciences Program, Duke Cancer Institute, Durham, NC, USA

${ }^{2}$ Department of Population Health Sciences, Duke University School of Medicine, 2424 Erwin Road, Suite 602, Durham, NC 27705, USA

Full list of author information is available at the end of the article
}

(c) The Author(s). 2020 Open Access This article is licensed under a Creative Commons Attribution 4.0 International License, which permits use, sharing, adaptation, distribution and reproduction in any medium or format, as long as you give appropriate credit to the original author(s) and the source, provide a link to the Creative Commons licence, and indicate if changes were made. The images or other third party material in this article are included in the article's Creative Commons licence, unless indicated otherwise in a credit line to the material. If material is not included in the article's Creative Commons licence and your intended use is not permitted by statutory regulation or exceeds the permitted use, you will need to obtain permission directly from the copyright holder. To view a copy of this licence, visit http://creativecommons.org/licenses/by/4.0/ The Creative Commons Public Domain Dedication waiver (http://creativecommons.org/publicdomain/zero/1.0/) applies to the data made available in this article, unless otherwise stated in a credit line to the data. 


\section{Background}

Infection with the bacteria Helicobacter pylori (H. pylori) is the primary cause of stomach cancer, the 6th leading cause of death from cancer among African American men. Stomach cancer also accounts for the greatest difference in death rates between African American men and women, compared to non-Hispanic white men and women [1]. Approximately 30\% of Americans are chronically infected with $H$. pylori, with rates above $50 \%$ for men and women of color, including African Americans, Asian Americans, and Hispanics [2, 3]. Currently, there is no systematic $H$. pylori screening and eradication plan in the United States to prevent stomach cancer or other H. pylori-associated diseases (gastritis, peptic ulcers, and MALT lymphoma), even though $H$. pylori eradication therapy has been shown to be highly effective and feasible [4]. Moreover, clinical trials have found that treatment for $H$. pylori (generally 14 days of two antibiotics plus a proton pump inhibitor and/or bismuth therapy) reduces stomach cancer risk by up to 50\% [5]. Population-wide screening and treatment for $H$. pylori has also been estimated to be substantially cost-effective, even in lower-risk countries like the United States [6, 7].

There are multiple barriers to conducting populationwide screening and treatment for $\mathrm{H}$. pylori that may hinder large-scale eradication of this bacteria and diminish the promise of meaningful reductions in the rates of stomach cancers. Concerns arise as only a small percentage of individuals with $H$. pylori will go on to develop stomach cancer, and eradication treatment requires the use of multiple antibiotics which are not consistently effective due to increasing $H$. pylori antibiotic resistance and lack of medication adherence. As we ultimately seek to establish population-based precision prevention of stomach cancer through $H$. pylori eradication, we recognize that the first step is to engage the communities at highest risk to educate and support $H$. pylori screening for those who seek to reduce their stomach cancer risk.

We developed the Durham Initiative for Stomach Health (DISH), a community-engaged pilot study to assess the feasibility of an $H$. pylori screening and eradication approach. The ultimate aim is to reduce stomach cancer incidence in populations in Durham County, North Carolina, at highest risk, including African Americans. Durham is a majority minority city with African Americans comprising $39.7 \%$ of the population, Asians $5.2 \%$, Whites $48 \%$ and other races $7.5 \%$ [8]. For the present project, we sought to engage the local community to build and implement a stomach cancer education platform that included screening for $\mathrm{H}$. pylori and motivating $H$. pylori-positive participants to seek treatment through conversation with their primary care providers.

\section{Methods}

\section{Community and stakeholder engagement}

DISH was originally designed as a multi-phase study with initial work intended to provide $H$. pylori testing to those at highest risk, primarily African Americans, in the local Durham community. A summary of the initial planning, final project processes, and lessons learned, is shown in Table 1, and described in detail below.

As part of initial planning, we intended to gather input from three groups of stakeholders: health services and community-based researchers; community members; and local clinicians. Early meetings with the Recruitment Innovation Center, a center focused on optimizing recruitment into clinical studies, and the Community Engaged Research Initiative, a community-engaged capacity building core, both part of the Duke Clinical Translational Science Institute (CTSI), provided critical input suggesting that the DISH study team should seek out community collaborations with groups who have existing relationships with Duke clinical research. The Duke Cancer Institute's Office of Health Equity (OHE) had an existing 4-year relationship with a local, predominantly African American church. This church is led by a pastor strongly interested in improving the health of his community, and thus a potential good partner for DISH. This local church had previously collaborated with Duke Cancer Institute (DCI) to raise awareness around strategies to prevent and treat cancer, including educational events on prostate and colon cancer, clinical research and trials seminars, and health fairs.

In parallel with these conversations, DISH staff engaged with other key community members. The study principal investigator (ME) and research program leader (SC) presented the DISH protocol to both the African Methodist Episcopalian (AME) Zion Health Equity Advocates \& Liaisons (AME Zion HEAL) partnership and the DCI Office of Health Equity's Community Advisory Council to introduce the study, explain eligibility, enrollment, study procedures, and populations of interest, and most importantly, to gain insight from these community leaders on study details. The AME Zion HEAL is a partnership between 17 predominantly African American AME Zion churches and the Duke Clinical Translational Science Institute (CTSI). The goal of AME Zion HEAL is to increase health equity and improve health in the African American community through a partnership designed to cultivate trust and increase engagement in clinical research among the African American community. The DCI OHE Community Advisory Council is a vital component of the health disparities work of the DCI and is comprised of representatives from public and private agencies, community members, and persons concerned with the cancer needs and disparities in Durham and across North Carolina. 
Table 1 DISH Community and Stakeholder Engagement and Impact on Study Procedures

\begin{tabular}{|c|c|c|c|}
\hline & Initial project ideas & Final project processes & Impact of Study \\
\hline \multicolumn{4}{|l|}{ Stakeholder meetings } \\
\hline $\begin{array}{l}\text { Input from health services } \\
\& \text { community- based } \\
\text { researchers }\end{array}$ & $\begin{array}{l}\text { One-on-one meetings } \\
\text { with select faculty }\end{array}$ & $\begin{array}{l}\text { Roundtable meeting with experts } \\
\text { from throughout the continuum } \\
\text { of community outreach to policy } \\
\text { implementation }\end{array}$ & $\begin{array}{l}\text { Group feedback enhanced a bigger-picture } \\
\text { thinking of the overall goals, towards which } \\
\text { the current project would be a first step }\end{array}$ \\
\hline Input from community & $\begin{array}{l}\text { Development of a steering } \\
\text { committee }\end{array}$ & $\begin{array}{l}\text { Work with established community } \\
\text { advisory councils }\end{array}$ & $\begin{array}{l}\text { Capitalizing on already existing relationships } \\
\text { with the community is pragmatic and feasible }\end{array}$ \\
\hline Input from clinicians & Focus groups with clinicians & $\begin{array}{l}\text { One-on-one meetings with } \\
\text { clinicians }\end{array}$ & $\begin{array}{l}\text { Clinicians have little time, so arranging } \\
\text { one-on-one meetings on their schedules } \\
\text { is more practical }\end{array}$ \\
\hline
\end{tabular}

\section{Study planning}

How to approach potential Meet with church pastor study participants

How to describe the study Study flyer

\section{Participant recruitment}

Location

No. of events and sites

Date and timing of event

Consent

Study enrollment

\section{Study event}

Questionnaire

Biospecimen Collection

Participant reimbursement Amazon gift card

No return of individual results

$\begin{array}{ll}\text { Individual results } & \begin{array}{l}\text { No return of individual } \\ \text { results }\end{array}\end{array}$

Meet with church pastor; present during Sunday services; meet with congregants

Study flyer, study brochure, in-person meetings at the church to explain the project

Community (at a local church)

One-day event on site at one church

All-day Tuesday prior to evening services

Electronic + in-person consent

Online + in-person enrollment

Shorten as much as possible remove religiosity questions, but add questions to help think about long-term implementation

Breath test and blood draw

Walmart gift card plus boxed meal, social security number waiver received

Results mailed to participant with an accompanying phone call by study team within 2 weeks of study event

Follow-up events at church to re-test after treatment
Importance of meeting the congregation and introducing the topic personally, and presenting the project as a cancer prevention strategy rather than focus on disparity

Interacting with potential study participants in multiple ways allows for an iterative process to best share study information

Individuals are most comfortable at sites they frequent and trust

Scaling down to for ease of execution and assessment of logistics

Provides flexibility for potential participants

To make the event logistics work more smoothly, make as many tasks available to be completed prior to the day of event as possible

(see above)

Participants need to feel that the questions are reasonable, not invasive (like religiosity questions), but that also get to the larger issues of beliefs/behavior, physician interaction, and finances

The stool sample would not have added significantly more information, but would create an additional barrier to participation.

Walmart was favored by this community; participation during lunch or dinner hour highlighted importance of boxed meal; requiring a social security number provides an additional barrier.

There is value and need to give back to participants. Follow-through includes: staff phone-calls to results, patient navigators provided to those with financial barriers, and physician executive summary to inform guideline-concordant $H$. pylori treatment.

There is documented $\sim 30 \%$ failure of $H$. pylori treatment to eradicate; re-testing allows us to re-visit the community, confirm eradication or to support seeking of salvage treatment. 
From these meetings valuable information was gained regarding study processes and questionnaire details, which allowed us to amend the data collection tools accordingly, as shown in Table 1. One-on-one meetings were also held with primary care physicians to gain knowledge about $H$. pylori treatment and policy, and moreover to attempt to understand their varied clinical perspectives regarding our proposed project, which includes activation of $H$. pylori-positive individuals with their primary care providers. From these interactions with clinicians, we determined the need for a one-page Physician Executive Summary, including approved treatment regimens, to accompany the results of a positive $H$. pylori test that the study participants could then share with their provider.

\section{Study planning}

Reflecting DISH team goals, and informed by key stakeholders, it was determined that the first phase of DISH would be a screening and education project onsite at a church that was acquainted with clinical research, beginning with a one-day enrollment event. OHE facilitated a meeting of DISH staff with the church leader as described above that allowed the DISH principal investigator and research program leader to visit the church to meet with the pastor and begin the conversation about H. pylori, stomach cancer, and health disparities, as well as the feasibility of hosting a study event at his church. From this initial meeting, common ground on the mutual goals of improving the health of the congregation was established, aiding in the building of trust and partnership. The pastor also gave invaluable insight into the presentation and communication of the study to the congregation, emphasizing that the DISH team should focus on the aspect of the study that allows individuals to make a positive step in reducing their stomach cancer risk, rather than on the statistics of racial disparity for this disease. The pastor and study team also agreed on the necessity of a commitment to the partnership, including follow-up after the initial study event was complete. Thus, with the full partnership of the pastor and critical input into the study approach, this church was chosen to be the flagship site for the study.

One week prior to the established date for the enrollment event, DISH staff attended Sunday church services to meet the congregation, introduce the topic of $\mathrm{H}$. pylori and its role in gastric cancer development, explain the study, inform interested congregants how to sign up for the event, and hand out flyers. The DISH flyer included information about the study, including the web address to the online enrollment link (see Supplemental Fig. 1). This allowed potential participants to access the link to determine eligibility, view and sign the e-consent, and fill out the study questionnaire. As informed by stakeholders, the website was created to reduce the amount of time each participant spent at the enrollment event. The church pastor also posted information regarding the enrollment event on his social media pages and posted a video discussing the event with the principal investigator on his YouTube channel.

\section{Participant recruitment}

Decisions regarding participant recruitment were made in collaboration with the pastor of the church. Specifically, the one-day event to screen for $H$. pylori would happen on-site at the church, where potential participants would be most comfortable, and would take place on a Tuesday, from 1 $\mathrm{pm}$ to $9 \mathrm{pm}$ prior to, during, and after church services that evening. While we had originally planned for the event on a Sunday, church partners advised that potential participants were unlikely to stay after services (which end at lunchtime), and a longer, weekday event, would allow for greater flexibility for participants. Concern about the logistics of many people showing up at one time, but needing first to go through the informed consent process, as well as fill out a lengthy questionnaire, led to the development of an econsent as well as online questionnaire that individuals could complete prior to the one-day study event. We also decided to provide tablets at the church for individuals to utilize on-site, and had paper copies of all materials (consent and questionnaire) available for those who were more comfortable completing the documents in that fashion.

Inclusion criteria for participation included age 40 or older and with the ability to provide informed consent in English. Exclusion criteria related to the ability for a breath test for assessment of $H$. pylori infection to produce accurate results, and included the use of antibiotics, Pepto Bismol, or any proton pump inhibitor in the past 2 weeks prior to enrollment, as well as prior gastric surgery and/or gastric cancer. At the study event, after meeting inclusion/exclusion criteria and consenting, individuals were screened for $H$. pylori infection with a breath test, as well as asked to complete a questionnaire and donate a blood sample. The blood sample was analyzed using multiplex serology for secondary analyses [9]. The results of the $H$. pylori breath test were then mailed to participants within 2 weeks of the enrollment event, and DISH staff followed up with all H. pylori-positive individuals by phone within 3 months, and with an additional breath test 6 months later. A second followup event was added 2 months later to ensure that all $H$. pylori-positive participants who were interested and could not attend the 6-month event were re-tested.

\section{Study event}

Study procedures

The DISH study event was planned for Tuesday, May 15, 2018 in one large room at the church. On the day of 
the event, study staff met with community members when they entered the study room to confirm the participants met the eligibility criteria, had reviewed and signed the study consent, and had completed the study questionnaire. Individuals who completed some or all of these documents online, as well as individuals who had not visited the study website previously, were welcome to participate. As necessary, DISH staff directly administered the questionnaire with study participants.

After consent was obtained and the study questionnaire begun, participants moved to various, marked tables for 1) the blood draw and 2) the breath test. Study staff administered the breath test and nurses/phlebotomists drew the blood sample. In between participants completed the questionnaire if necessary, and/or waited at tables with fellow participants. After participants completed all study procedures, they received a gift card and boxed dinner, as participants had to fast for an hour prior to taking the breath test, as required by the manufacturer.

\section{Breath test}

The Helicobacter pylori Urea Breath Test, Infra-red $\left(\mathrm{UBiT}^{\circ}\right)$, is a non-invasive, non-radioactive method for detecting urease associated with $H$. pylori infection by measuring labelled carbon dioxide in the subject's breath. To take the breath test, the participant exhaled into a balloon-like bag for a baseline sample, then drank a small amount of a lemon-flavored solution, which included 13C-urea - urea labeled with a non-radioactive carbon isotope. The participant remained seated for 15 min, after which they exhaled into another balloon-like bag. After sample collection, the bags with the exhaled breath samples were mailed to Quest Diagnostics for testing. An increase in the ratio of $13 \mathrm{CO} 2$ to $12 \mathrm{CO} 2$ between pre- and post-ingestion samples indicates the presence of $H$. pylori-associated urease [10].

\section{Questionnaire}

The 12-page questionnaire sought to capture all potentially relevant gastric cancer risk factors, plus detailed lifestyle variables. A list of the variables included in the baseline questionnaire is provided in Table 2 .

To measure current gastric symptoms, the Gastrointestinal Symptom Rating Scale (GSRS) was used. The GSRS is a disease-specific instrument used to evaluate common symptoms of gastrointestinal disorders. This scale contains 15 questions with a seven-point Likert

Table 2 Questionnaires

\begin{tabular}{|c|c|}
\hline Category & Variables \\
\hline \multicolumn{2}{|l|}{ Baseline Questionnaire } \\
\hline Demographics & Age, race, ethnicity, education, income, occupation \\
\hline Gastric Symptoms & $\begin{array}{l}\text { Stomach ache, heartburn, acid reflux, hunger pains, nausea, rumbling in stomach, feeling bloated, burping, passing gas, } \\
\text { constipation, diarrhea, loose stools, hard stools, urgent need to have bowel movement, not completely emptying bowels }\end{array}$ \\
\hline Family History & Cancer, 1st degree relatives, if occurred before age 50; stomach ulcers, gastritis, $\mathrm{H}$. pylori \\
\hline Medication Use & Use of antibiotics, aspirin, acetaminophen, peptic ulcer medication, pills for diabetes, insulin, allergy pills, asthma \\
\hline Medical History & $\begin{array}{l}\text { Heart trouble, high blood pressure, anemia, asthma, hayfever, skin allergy, food allergy, emphysema, COPD, stomach ulcer, } \\
\text { duodenal ulcer, IBD, gastritis, H. pylori, GERD, heartburn, pancreatitis, TB, hepatitis, HPV, MS, diabetes }\end{array}$ \\
\hline Cancer Screening & $\begin{array}{l}\text { Women (pap smear, mammogram, sigmoidoscopy, colonoscopy), men (digital rectal exam, PSA blood test, sigmoidoscopy, } \\
\text { colonoscopy) }\end{array}$ \\
\hline Smoking & Smoking status, number per day, age first smoked, number of years; chewing tobacco, snuff/dip, pipes, cigars \\
\hline Alcohol & Current use, type of drink, amount and how often \\
\hline Physical Activity & Average sleep during week/week-end, vigorous and moderate activity, walking, sitting \\
\hline Height and weight & Self-reported height/weight \\
\hline \multicolumn{2}{|c|}{ Follow-up Questionnaire } \\
\hline Gastric Symptoms & Same as those in the baseline questionnaire (Table 2 above) \\
\hline Family History & Any 1st degree relatives during the past six months being diagnosed with cancer, ulcers, gastritis, $H$. pylori \\
\hline Medical History & Changes in the past 6 months regarding anemia, stomach ulcer, duodenal ulcer, IBD, gastritis, GERD, diabetes \\
\hline $\begin{array}{l}\text { Interaction with } \\
\text { doctor }\end{array}$ & $\begin{array}{l}\text { Hp + only - communication with doctor about infection (in person, over the phone, via email), timeline from diagnosis to } \\
\text { doctor's visit, did doctor re-test prior to treatment, did doctor retest after treatment, what was prescribed (number of pills/ } \\
\text { day/duration), adherence to prescribed medication, cost }\end{array}$ \\
\hline $\begin{array}{l}\text { Experience with } \\
\text { physician }\end{array}$ & $\begin{array}{l}\text { Scale of very poor, poor, fair, good, very good; friendliness, explanation about their condition, concern about questions/ } \\
\text { worries, involvement in decision making, information about medications, follow-up care, amount of time spent with pro } \\
\text { vider, confidence in provider, recommend provider }\end{array}$ \\
\hline Height and weight & Self-reported height/weight \\
\hline
\end{tabular}


scale ranging from no discomfort to very severe discomfort. These fifteen questions were then broken down into four categories - abdominal pain (stomach pain, hunger pains, nausea), reflux syndrome (heartburn, acid reflux), diarrhea syndrome (diarrhea, loose stools, bowel urgency), indigestion syndrome (rumbling, bloating, burping, passing gas) and constipation syndrome (constipation, hard stools, feeling of incomplete evacuation) [11].

Study data were collected and managed using REDCap electronic data capture tools hosted at Duke University [12].

\section{Follow-up}

Within 2 weeks after the study event, participants were mailed a letter informing them whether they had a current $H$. pylori infection. If the report was a positive breath test, the letter explained what is known about the association of infection with $H$. pylori and gastric cancer risk, along with a recommendation that the individual speaks with their primary care physician. $H$. pylori-positive individuals also received a "Physician Executive Summary," to share with their primary care provider, which listed approved $H$. pylori eradication therapy treatments. Producing a counseling document to the physician that outlines treatment options can produce higher eradication rates, and was recommended during one of the one-on-one preparatory meetings DISH staff had with a primary care physician. Moreover, there is evidence that counseling of primary care providers improves appropriate $H$. pylori treatment and eradication rates $[13,14]$. Participants also received a toll-free number in case they had questions that needed immediate attention. Additionally, participants were informed that if they did not have a regular primary care physician or

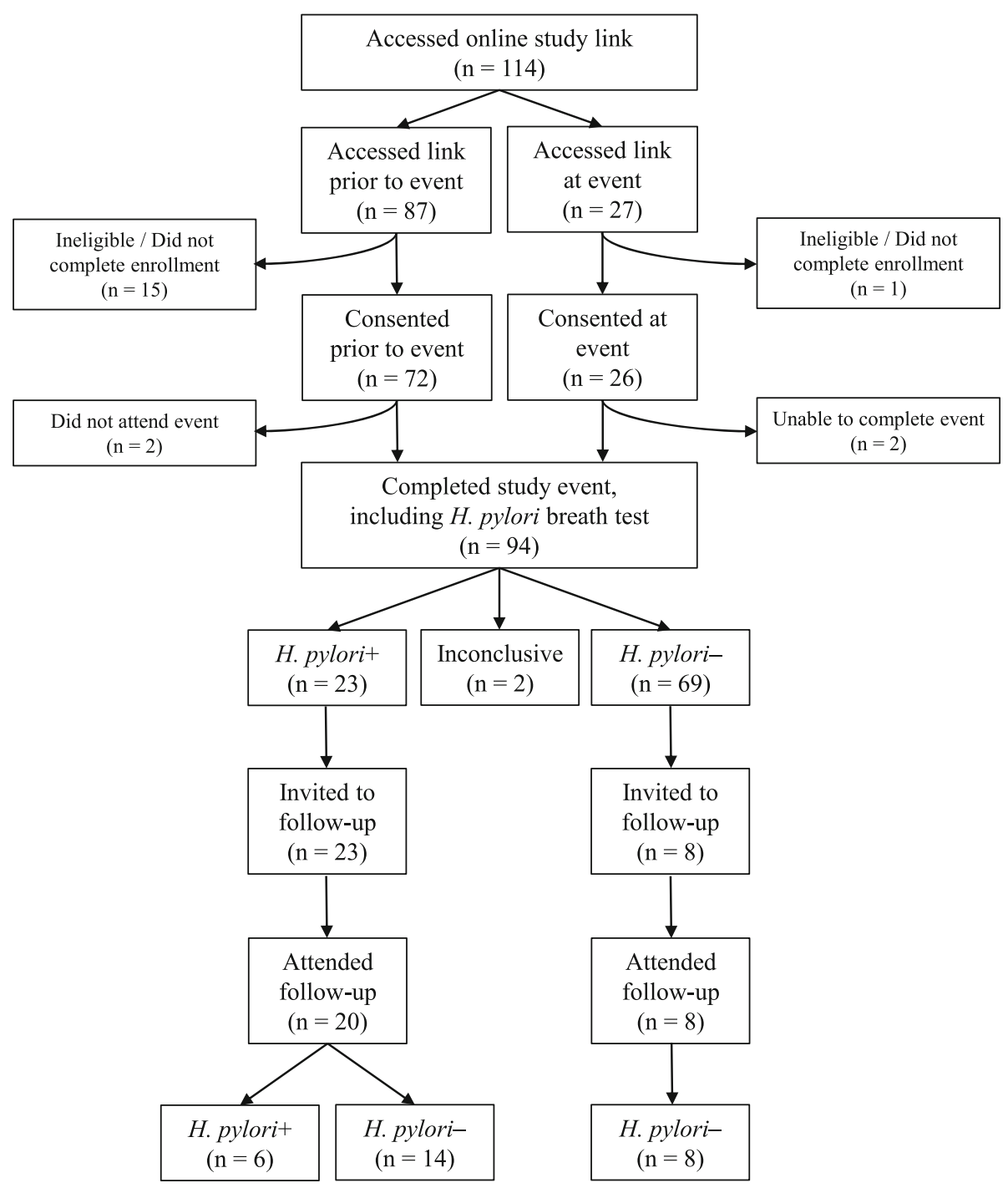

Fig. 1 Flowchart of the DISH Study 
health insurance, DISH staff would put them in touch with a patient navigator from OHE.

Approximately 3 months after the initial enrollment event, $H$. pylori positive participants were contacted by phone to ask if they had sought treatment. Additionally, participants identified at this point who were without insurance were referred to patient navigators from OHE to link them with physicians who could treat their infection at no or a reduced cost.

After the initial enrollment, two separate follow-up events were held at the church (one at 6 months, the other at 8 months). These follow-up events were for participants who tested positive for $H$. pylori, along with a sample of $H$. pylori-negative participants, to determine the percent treated, and among those, the percent successfully eradicated by a follow-up breath test, as well as to collect information on H. pylori-positive participants' interactions with their primary care providers. Information on financial costs incurred by the participants was also requested. Those individuals found to be $H$. pyloripositive at the follow-up event were given a second letter and physician summary to bring to their primary care physician. A more detailed listing of variables in the follow-up questionnaire is given in Table 2 .

\section{Results}

\section{Participant accrual}

As illustrated in Fig. 1, 114 community members accessed the online enrollment link in an effort to begin the eligibility and consenting process, as well as to fill out the study questionnaire. Eighty-seven accessed the online enrollment link prior to the DISH event, with 72 of the 87 (83\%) completing the eligibility, consent and questionnaire prior to the event.

In total, 94 individuals successfully participated in the enrollment event, close to our goal of 100 participants. Of the 94 who participated, two had inconclusive breath test results and were not included in the analyses of results. These two community partners were offered retesting, and one did come back for a second breath test, but it too was inconclusive. Inconclusive breath test results occur in $1-2 \%$ of a patient population [15].

\section{Participant characteristics}

Of the 92 participants included in the analyses of $\mathrm{H}$. pylori prevalence, the majority identified as African American (97\%), female (79\%), never smokers (79\%), not current drinkers (64\%), having an associate's degree or higher (53\%), an annual income of $\$ 50,000$ or more (54\%), and with health insurance (90\%). Most participants had never been regular aspirin users (67\%), and while participants reported high blood pressure (54\%), anemia (37\%), and allergies (30\%), the prevalence of other chronic health conditions was relatively low in this population (see Table 3).

\section{H. pylori prevalence}

Overall, $25 \%$ of participants with a conclusive breath test were determined to have a current $H$. pylori infection (see Fig. 1). As shown in Table 3, there were no significant differences between $H$. pylori-positive and -negative individuals by any demographic or medical history characteristics.

\section{3-month phone follow-up}

Three months after the main DISH event, study staff sought to re-contact all $23 \mathrm{H}$. pylori-positive participants to learn of the participants' follow-on actions, specifically communicating with their primary care providers and seeking treatment. DISH staff ultimately made contact with $74 \%$ of the $H$. pylori-positive participants (17 of 23), and $82 \%$ (14 of 17) reported having seen their doctor and being prescribed medication for their infection. DISH staff used this opportunity to encourage those $H$. pylori-positive individuals who had not yet sought treatment to speak with their primary care physician. Two of the three participants who had not sought care were referred to patient navigators through OHE.

\section{In-person follow-up events}

All $23 H$. pylori-positive participants and a subset of $H$. pylori-negative participants $(n=8)$, for comparison, were invited back for the DISH follow-up events to re-test for active $H$. pylori infection. Twenty (87\%) of the $H$. pyloripositive participants participated in the follow-up events along with all $8(100 \%)$ of the $H$. pylori-negatives. The three $H$. pylori-positive participants who did not attend were contacted and offered a second breath test, with one returning for the follow-up breath test at a later date. At the follow-up events, $70 \%$ (14 of 20) of $\mathrm{H}$. pylori-positive participants had their infection eradicated, leaving 30\% (6 of 20) with a persistent $H$. pylori infection (see Fig. 1). All H. pylori-negative participants at the initial event who were re-tested remained negative at the follow-up events.

\section{Follow-up survey}

As part of the follow-up events, participants were asked if there were any changes within the past 6 months regarding their personal medical history or family history of cancer, ulcers, or gastritis. One $H$. pylori-negative participant stated a family member had recently been diagnosed with ulcers. All others answered these questions as 'none diagnosed.'

Physician interaction questions were based on a 5point Likert scale from the Press Ganey Patient Satisfaction Survey with values of very poor, poor, fair, good, 
Table 3 Study participant characteristics

\begin{tabular}{|c|c|c|c|}
\hline & All $N=92)$ & H. pylori negative $N=69$ ) & H. pylori positive $N=23$ ) \\
\hline \multicolumn{4}{|l|}{ Age } \\
\hline Mean (SD) & $53.9(8.9)$ & $53.4(8.9)$ & $55.6(8.6)$ \\
\hline Range & $(40.8-76.6)$ & $(40.8-71.9)$ & $(43.1-76.6)$ \\
\hline \multicolumn{4}{|l|}{ Sex, N (\%) } \\
\hline Female & $73(79.3)$ & $57(82.6)$ & $16(69.6)$ \\
\hline Male & $19(20.7)$ & $12(17.4)$ & $7(30.4)$ \\
\hline \multicolumn{4}{|l|}{ Race, N (\%) } \\
\hline African American & $89(96.7)$ & $66(95.7)$ & $23(100.0)$ \\
\hline Other & $3(3.3)$ & $3(4.3)$ & $0(0.0)$ \\
\hline \multicolumn{4}{|l|}{ Smoking, N (\%) } \\
\hline Ever & $19(20.7)$ & $16(23.2)$ & $3(13.0)$ \\
\hline Never & $73(79.3)$ & $53(76.8)$ & $20(87.0)$ \\
\hline \multicolumn{4}{|l|}{ Alcohol use, N (\%) } \\
\hline Currently & $33(35.9)$ & $27(39.1)$ & $6(26.1)$ \\
\hline Never & $31(33.7)$ & $23(33.3)$ & $8(34.8)$ \\
\hline Used to & $28(30.4)$ & $19(27.5)$ & $9(39.1)$ \\
\hline \multicolumn{4}{|l|}{ Education, N (\%) } \\
\hline No high school degree & $2(2.2)$ & $2(2.9)$ & $0(0.0)$ \\
\hline High school but no college degree & $41(44.6)$ & $27(39.1)$ & $14(60.9)$ \\
\hline Associates degree or higher & $49(53.3)$ & $40(58.0)$ & $9(39.1))$ \\
\hline \multicolumn{4}{|l|}{ Income, N (\%) } \\
\hline Missing & 3 & 1 & 2 \\
\hline$<\$ 10,000$ & $4(4.5)$ & $4(5.9)$ & $0(0.0)$ \\
\hline$\geq \$ 10,000-\$ 24,999$ & $4(4.5)$ & $4(5.9)$ & $0(0.0)$ \\
\hline$\geq \$ 25,000-\$ 49,999$ & $41(46.1)$ & $30(44.1)$ & $11(52.4)$ \\
\hline$\geq \$ 50,000-\$ 74,999$ & $15(16.9)$ & $10(14.7)$ & $5(23.8)$ \\
\hline$\geq \$ 75,000-\$ 100,000$ & $15(16.9)$ & $13(19.1)$ & $2(9.5)$ \\
\hline$>\$ 100,000$ & $10(11.2)$ & $7(10.3)$ & $3(14.3)$ \\
\hline \multicolumn{4}{|l|}{ Health insurance, N (\%) } \\
\hline No & $9(9.8)$ & $7(10.1)$ & $2(8.7)$ \\
\hline Yes & $83(90.2)$ & $62(89.9)$ & $21(91.3)$ \\
\hline \multicolumn{4}{|l|}{ BMI, N (\%) } \\
\hline$\leq 25$ & $10(10.9)$ & $9(13.0)$ & $1(4.3)$ \\
\hline$>25-30$ & $26(28.3)$ & $17(24.6)$ & $9(39.1)$ \\
\hline$>30-35$ & $27(29.3)$ & $19(27.5)$ & $8(34.8)$ \\
\hline$>35$ & $29(31.5)$ & $24(34.8)$ & $5(21.7)$ \\
\hline \multicolumn{4}{|l|}{ Regular aspirin use, $\mathrm{N}(\%)$} \\
\hline Current & $12(13.0)$ & $6(8.7)$ & $6(26.1)$ \\
\hline Former & $18(19.6)$ & $14(20.3)$ & $4(17.4)$ \\
\hline Never & $62(67.4)$ & $49(71.0)$ & $13(56.5)$ \\
\hline \multicolumn{4}{|l|}{ Medical history, N (\%) } \\
\hline High blood pressure & $50(54.3)$ & $36(52.2)$ & $14(60.9)$ \\
\hline Anemia & $34(37.0)$ & $29(42.0)$ & $5(21.7)$ \\
\hline Allergies & $28(30.4)$ & $22(31.9)$ & $6(26.1)$ \\
\hline
\end{tabular}


Table 3 Study participant characteristics (Continued)

\begin{tabular}{llll}
\hline & All $N=92)$ & H. pylori negative $N=69)$ & H. pylori positive $N=23)$ \\
\hline Asthma & $14(15.2)$ & $11(15.9)$ & $3(13.0)$ \\
Type 2 diabetes & $16(17.4)$ & $13(18.8)$ & $3(13.0)$ \\
GERD & $11(12.0)$ & $9(13.0)$ & $2(8.7)$ \\
Heartburn & $8(8.7)$ & $6(8.7)$ & $2(8.7)$ \\
IBD & $5(5.4)$ & $5(7.2)$ & $0(0.0)$ \\
Gastritis & $5(5.4)$ & $4(5.8)$ & $1(4.3)$ \\
Stomach ulcer & $5(5.4)$ & $5(7.2)$ & $0(0.0)$ \\
\hline
\end{tabular}

and very good [16]. In general, $H$. pylori-positive individuals reported positive experiences during their visit to request treatment for their infection, with the majority reporting good or very good experiences to the physician interaction questions (see Table 4). However, only a small percentage of $H$. pylori-positive individuals (3 of 20) reported that their provider followed up with them after treatment to confirm eradication, which is necessary to provide guideline-concordant care according to the American College of Gastroenterology [4].

Participants were again asked the gastric distress questions at follow-up. There were no significant differences by $H$. pylori status or changes from the initial event to the six-month follow-up event for any gastric distress symptom, among those with cleared, persistent, or no infection.

\section{Discussion}

With 92 participants and $87 \%$ follow-up of $H$. pyloripositive individuals, this pilot $H$. pylori screening and eradication study, conducted with an engaged community partner, demonstrated feasibility and acceptability.

The success of this study was supported through active collaboration with multiple community stakeholders. Specifically, the knowledge and understanding gained from all who participated in planning the study - community groups, clinicians, health community-based researchers - prior to its initiation enabled a larger understanding of the situation in which the project would be conducted, and ultimately informed all aspects of the study materials, logistics, and follow-up. We had many iterations to our study documents based on input from these meetings, making the data collection tools more acceptable and relevant to our community and intended user. Importantly, partnering with a community group that had previously been introduced to the DCI and its research, including a pastor who is very involved in the health promotion of his congregants and the larger community, enabled a setting of trust that allowed for an onsite clinical study.

We found that building trust and creating relationships with the community was essential when implementing a study that involves biospecimen collection and the sharing of personal information. It is also necessary to set aside adequate time to talk about the study with potential participants and keep those lines of communication open during and after the study. Most importantly, we found that engaging with the participants to fully understand their needs, concerns, and experiences is critical. For example, one participant has had stomach distress for years, resulting in a hospital stay where she was asked to take the breath test for $H$. pylori, but at the time refused because the process and rationale of the breath test - drinking a yellow-colored liquid and

Table 4 Experience with care provider among H. pylori-positive individuals who sought care

\begin{tabular}{ll}
\hline Variable & \% reporting good or very good experience \\
\hline Confidence in provider & $100 \%$ \\
Likelihood of recommending this provider to others & $95 \%$ \\
Explanations the provider gave about H. pylori infection & $95 \%$ \\
Information the provider gave about medications & $95 \%$ \\
Concern the provider showed for patient's questions or worries & $90 \%$ \\
Provider used words they could understand & $90 \%$ \\
Provider included them in decision about their treatment & $85 \%$ \\
Friendliness/courtesy of the provider & $75 \%$ \\
Amount of time provider spent with them & $74 \%$ \\
Instructions about follow-up care & $72 \%$ \\
\hline
\end{tabular}


blowing into a bag - was not clearly communicated to her. After our church engagement, testing, and recommendations, she received treatment, eradicated her $H$. pylori, and now feels significantly better. Moreover, we plan to return to the church with the overall results as presented here, to communicate the important role our community partners played in this successful pilot project.

Overall, 23\% of participants in DISH were found to have an active $H$. pylori infection, which is below the national average estimates of $30 \%$ for the general population and 50\% for African Americans [3]. While the prevalence of $H$. pylori in this community was lower than expected from national statistics, this could be attributed to the study population differing from a more general African American population. For example, this study population including a larger representation of women who are often seen to be less likely to be infected with $H$. pylori $[2,17]$, and suggesting that greater effort is needed to encourage men to participate in screening. This population was also composed of individuals of higher average socio-economic status, who are less likely to be infected with $H$. pylori.

As only $70 \%$ of $H$. pylori-positive DISH participants successfully eradicated their bacteria, additional research is needed to address the issues of antibiotic resistance and medication adherence, as well as physician followup $[18,19]$. While our eradication rate was below the estimated national norm of $80 \%$ [20], it has been suggested that eradication could be up to $95 \%$ effective if there is patient adherence and treatment based on knowledge regarding local H. pylori antibiotic resistance [21]. During our study, one participant determined to have a persistent $H$. pylori infection met with their physician who decided to perform an endoscopy, and subsequently found multiple ulcers. The physician sent the tissue to be tested for antibiotic resistance and found that the participant's $H$. pylori was resistant to clarithromycin. Because of this, a different therapy was prescribed. The most recent endoscopy showed the ulcers healing and the patient has cleared their $H$. pylori infection. The challenge of medication adherence is illustrated by one DISH participant, who, unaware of the adverse effects, stopped taking the prescribed medication 4 days early and was found to have a persistent infection during the DISH follow-up. Approximately $50 \%$ of patients with a chronic illness do not take medications as prescribed, which can contribute to increased health care costs as well as negative health outcomes for patients [22, 23]. In our followup surveys, we were unable to detect the reason for lack of eradication among the other participants, suggesting the concerns nationally of $H$. pylori antibiotic-resistant strains and physician and/or patient non-adherence to treatment and/or medication guidelines may be the main causes.

A lack of physician follow-up is an additional challenge. The American Clinical Guidelines recommendation is to test patients after treatment therapy for eradication determination, but it is estimated that only 20 to $40 \%$ of primary care physicians confirm H. pylori eradication, with only slightly higher rates among gastroenterologists [18, 24, 25]. However, education of clinicians to this clinical guideline can improve retesting for eradication [13].

\section{Conclusions}

In conclusion, the DISH study sought to assess the acceptability and feasibility of an $H$. pylori education and screening study, to more finely characterize the prevalence of infection with $H$. pylori in an African American church-based population in the local Durham, North Carolina area, and the opportunities for targeted eradication therapy. We have demonstrated that by engaging with stakeholders in an iterative fashion, and building trust and cultivating relationships with potential study populations, such a study is indeed possible. This pilot study also illustrated remaining issues to be resolved prior to the initiation of larger eradication trials. Specifically, these issues include improving $H$. pylori eradication rates through increasing antibiotic resistanceinformed treatment, patient medication adherence, and physician follow-up to confirm eradication, barriers that need to be addressed by clinicians and researchers within and beyond the context of minority health.

\section{Supplementary information}

Supplementary information accompanies this paper at https://doi.org/10. 1186/s12876-020-01405-w.

Additional file 1: Supplemental Figure 1. DISH Study Flyer.

\section{Abbreviations}

AME Zion HEAL: African Methodist Episcopalian Zion Health Equity Advocates \& Liaisons; CTSI: Clinical Translational Science Institute; DCl: Duke Cancer Institute; DISH: Durham Initiative for Stomach Health;

GSRS: Gastrointestinal Symptom Rating Scale; H. pylori: Helicobacter pylori; OHE: Office of Health Equity

\section{Acknowledgements}

The authors thank the members of the River Church and of the Office of Health Equity at the Duke Cancer Institute for their partnership and contributions to this research.

\section{Authors' contributions}

SC and ME were responsible for all aspects of the study including study design, processes, collection and analysis of data, and writing of the first draft of the manuscript. JB, JMG, NJB, SMB, KO, and SP aiding in designing the study, interpreting the data, and editing the manuscript. WW and RG were significantly involved in study design and recruitment. All authors read and approved the final manuscript. 


\section{Funding}

Funding for this project was provided by a CTSA grant (UL1TR002553) and the Duke Cancer Institute. The content is solely the responsibility of the authors and does not necessarily represent the official views of the funders. The funders did not have an influence on the design of the study and collection, analysis, and interpretation of data and in writing the manuscript.

\section{Availability of data and materials}

The datasets generated and/or analysed during the current study are not publicly available due to the small numbers and a publicly identified community partner, but are available from the corresponding author on reasonable request.

\section{Ethics approval and consent to participate}

The DISH study received approval from the Duke University Health System Institutional Review Board for Clinical Investigations (Pro00088728). Informed consent in the form of both e-consent and written consent was approved and obtained from all individual participants in the study.

\section{Consent for publication}

Not applicable.

\section{Competing interests}

The authors declare that they have no competing interests.

\section{Author details}

${ }^{1}$ Cancer Control and Population Sciences Program, Duke Cancer Institute, Durham, NC, USA. ${ }^{2}$ Department of Population Health Sciences, Duke University School of Medicine, 2424 Erwin Road, Suite 602, Durham, NC 27705, USA. ${ }^{3}$ Center of Innovation to Accelerate Discovery and Practice Transformation, Durham Veterans Affairs Medical Center, Durham, NC, USA. ${ }^{4}$ Department of Family Medicine and Community Health, Duke University School of Medicine, Durham, NC, USA. ${ }^{5}$ Duke Clinical and Translational Science Institute, Duke University School of Medicine, Durham, NC, USA. ${ }^{6}$ Department of Medicine, Duke University School of Medicine, Durham, NC, USA. 'Department of Pharmacology and Cancer Biology, Duke University School of Medicine, Durham, NC, USA. ${ }^{8}$ The River Church, Durham, NC, USA.

Received: 18 February 2020 Accepted: 29 July 2020

Published online: 06 August 2020

\section{References}

1. DeSantis CE, Miller KD, Goding Sauer A, Jemal A, Siegel RL. Cancer statistics for African Americans, 2019. CA Cancer J Clin. 2019;69(3):211-33.

2. Epplein M, Signorello LB, Zheng W, Peek RM Jr, Michel A, Williams SM, et al. Race, African ancestry, and helicobacter pylori infection in a low-income United States population. Cancer Epidemiol Biomark Prev. 2011;20(5):826-34.

3. McQuillan GM, Kruszon-Moran D, Kottiri BJ, Curtin LR, Lucas JW, Kington RS. Racial and ethnic differences in the seroprevalence of 6 infectious diseases in the United States: data from NHANES III, 1988-1994. Am J Public Health. 2004;94(11):1952-8.

4. Chey WD, Leontiadis Gl, Howden CW, Moss SF. ACG clinical guideline: treatment of helicobacter pylori infection. Am J Gastroenterol. 2017;112(2): 212-39.

5. Lee YC, Chiang TH, Chou CK, Tu YK, Liao WC, Wu MS, et al. Association between helicobacter pylori eradication and gastric Cancer incidence: a systematic review and meta-analysis. Gastroenterology. 2016;150(5):1113-24 e5.

6. Lansdorp-Vogelaar I, Sharp L. Cost-effectiveness of screening and treating helicobacter pylori for gastric cancer prevention. Best Pract Res Clin Gastroenterol. 2013;27(6):933-47.

7. Parsonnet J, Harris RA, Hack HM, Owens DK. Modelling cost-effectiveness of helicobacter pylori screening to prevent gastric cancer: a mandate for clinical trials. Lancet. 1996;348(9021):150-4.

8. $\quad$ U.S. Census Bureau American Community Survey 5-year Estimates 20132017 [Available from: https://www.census.gov/en.html.

9. Butt J, Blot WJ, Shrubsole MJ, Varga MG, Hendrix LH, Crankshaw S, et al. Performance of multiplex serology in discriminating active vs past Helicobacter pylori infection in a primarily African American population in the southeastern United States. Helicobacter. 2019;25:e12671.

10. Skrebinska S, Megraud F, Bessede E. Diagnosis of Helicobacter pylori infection. Helicobacter. 2018;23(Suppl 1):e12515.
11. Revicki DA, Wood M, Wiklund I, Crawley J. Reliability and validity of the gastrointestinal symptom rating scale in patients with gastroesophageal reflux disease. Qual Life Res. 1998;7(1):75-83.

12. Harris PA, Taylor R, Thielke R, Payne J, Gonzalez N, Conde JG. Research electronic data capture (REDCap)--a metadata-driven methodology and workflow process for providing translational research informatics support. J Biomed Inform. 2009;42(2):377-81.

13. Laredo V, Sostres C, Alfaro E, Arroyo MT, Lanas A. Management of Helicobacter pylori infection at the primary care level. The implementation of specific counseling improves eradication rates. Helicobacter. 2019;24(3): e12586.

14. Boltin D, Dotan I, Birkenfeld S. Improvement in the implementation of helicobacter pylori management guidelines among primary care physicians following a targeted educational intervention. Ann Gastroenterol. 2019; 32(1):52-9.

15. Gisbert JP, Pajares JM. Review article: 13C-urea breath test in the diagnosis of helicobacter pylori infection -- a critical review. Aliment Pharmacol Ther. 2004;20(10):1001-17.

16. Press Ganey Corporation. The Press Ganey Patient Satisfaction Survey [Available from: http://www.pressganey.com/.

17. Epplein M, Cohen SS, Sonderman JS, Zheng W, Williams SM, Blot WJ, et al Neighborhood socio-economic characteristics, African ancestry, and helicobacter pylori sero-prevalence. Cancer Causes Control. 2012;23(6):897-906.

18. Murakami TT, Scranton RA, Brown HE, Harris RB, Chen Z, Musuku S, et al. Management of Helicobacter Pylori in the United States: results from a national survey of gastroenterology physicians. Prev Med. 2017;100:216-22.

19. Pan KF, Zhang L, Gerhard M, Ma JL, Liu WD, Ulm K, et al. A large randomised controlled intervention trial to prevent gastric cancer by eradication of helicobacter pylori in Linqu County, China: baseline results and factors affecting the eradication. Gut. 2016;65(1):9-18.

20. Vakil N. Primary and secondary treatment for helicobacter pylori in the United States. Rev Gastroenterol Disord. 2005;5(2):67-72.

21. El-Serag HB, Kao JY, Kanwal F, Gilger M, LoVecchio F, Moss SF, et al. Houston consensus conference on testing for helicobacter pylori infection in the United States. Clin Gastroenterol Hepatol. 2018;16(7):992-1002 e6.

22. Bosworth HB, Fortmann SP, Kuntz J, Zullig LL, Mendys P, Safford M, et al. Recommendations for providers on person-centered approaches to assess and improve medication adherence. J Gen Intern Med. 2017;32(1):93-100.

23. Brown MT, Bussell JK. Medication adherence: WHO cares? Mayo Clin Proc. 2011;86(4):304-14

24. Boltin D, Kimchi N, Dickman R, Gingold-Belfer R, Niv Y, Birkenfeld S. Attitudes and practice related to helicobacter pylori infection among primary care physicians. Eur J Gastroenterol Hepatol. 2016;28(9):1035-40.

25. Hung KW, Knotts RM, Faye AS, Pont AR, Lebwohl B, Abrams JA, et al. Factors associated with adherence to helicobacter pylori testing during hospitalization for bleeding peptic ulcer disease. Clin Gastroenterol Hepatol. 2020;18(5):1091-8

\section{Publisher's Note}

Springer Nature remains neutral with regard to jurisdictional claims in published maps and institutional affiliations.

Ready to submit your research? Choose BMC and benefit from:

- fast, convenient online submission

- thorough peer review by experienced researchers in your field

- rapid publication on acceptance

- support for research data, including large and complex data types

- gold Open Access which fosters wider collaboration and increased citations

- maximum visibility for your research: over $100 \mathrm{M}$ website views per year

At $\mathrm{BMC}$, research is always in progress.

Learn more biomedcentral.com/submissions 